\title{
Mortality from non-malignant diseases among women in the meat industry
}

\author{
E S JOHNSON
}

From the Department of Epidemiology, the Johns Hopkins University School of Hygiene and Public Health, Baltimore, MD 21205, USA

ABSTRACT A mortality follow up study was conducted among 7261 white female members in a local meatcutter's union in Baltimore, Maryland, between July 1949 and December 1980. The group ${ }_{-}^{+}$ was divided into four main job categories within the meat industry and a control group of non-meato workers belonging to the same union. Mortality in each of these subgroups was compared with thato of white women in the United States general population through the determination of cause specific standardised mortality ratios. No increased risk of death from non-malignant causes was observede in any job category within the meat industry. Some caution should, however, be exercised in? interpretating this finding, as few workers in chicken slaughtering plants died.

The trigger that sets in motion an interest in studying mortality in a given industry has often been that a particular exposure, or exposures, within the industry are conceived or suspected to be potentially harmful. This general pattern, however, does not seem to have applied to the meat industry. It has been known, for example, that workers wrapping and labelling meat develop an acute condition known as "meatwrapper's asthma" as the result of exposure to fumes emitted during this activity from the thermal decomposition of plastic. ${ }^{1}$ This condition has been shown to be associated with upper and lower respiratory tract symptoms and a decrease in the forced expiratory volume in one second and forced vital capacity. Cattle and chickens at the time of slaughter are often found to be infected with viruses known to cause diseases of the blood and blood forming organs including leukaemia and lymphosarcoma in these animals. ${ }^{2-5}$ Workers in slaughterhouses and meatpacking plants are known to be at increased risk of zoonotic infections which include brucellosis, leptospirosis, Q-fever, and psittacosis. ${ }^{6}$ Other potentially harmful exposures in the industry include smoke during the smoking of meat, the nitrosamines formed during meat curing and storage, and certain tumour promoting antioxidants. ${ }^{7-10}$ Despite this array of potentially noxious exposures,

Present address: International Agency for Research on Cancer, 150 cours Albert-Thomas, 69372 Lyon, France.

Accepted 21 April 1986 there has been little interest in their possible effects. long after exposure has ceased. In particular, thereo has been no study on the mortality experience of women in the industry, although they constitute mosto of the workforce engaged in certain activities withino the industry; commonly more than $90 \%$ of the meat- $\triangle$ wrappers in retail food stores are women. ${ }^{11} \mathrm{We}$ con-ö ducted what was to our knowledge the first detailed 3 mortality study of women in the industry and reported on the findings for death from cancers. ${ }^{120}$ The present paper is a report on the non-cancer mor-o tality pattern among the same study group.

\section{Materials and methods}

The study population was derived from among the $\frac{3}{3}$ membership of a local meatcutter's union in Bal-o timore, Maryland, and has been described in detail elsewhere. ${ }^{12}$ They were followed up from July 1949 too December 1980 and the lost to follow up rate was $7 \cdot 6 \%$. Four main job categories in the industry were recognised within the union: (1) abattoir workers, (2) 0 meatpacking plant workers (no slaughtering done), N (3) workers in the meat department of retail food ${ }_{\sigma}^{\omega}$ stores, and (4) workers in chicken slaughtering plants. A fifth category of workers outside the industry (con- $-\frac{\mathrm{C}}{\mathrm{D}}$ trol group) was also identified among the union membership. A total of 7261 white women who had been members of the union between 1949 and 1979 were identified, and since over $95 \%$ (6923) worked in only $\overrightarrow{\mathbb{D}}$ one job category throughout their membership, these $\frac{}{\circ}$ 
Selected cause specific SMRs for white women in a local meatcutter's union in Baltimore, Maryland, by job category. (Figures in parentheses denote SMRs obtained when lost subjects were withdrawn at the time of loss)

\begin{tabular}{|c|c|c|c|c|c|c|}
\hline $\begin{array}{l}\text { Cause of death } \\
\text { (ICD, 8th revision) }\end{array}$ & $\begin{array}{l}\text { All groups } \\
(n=7261) \\
S M R\end{array}$ & $\begin{array}{l}\text { Abattoirs } \\
(n=826) \\
S M R\end{array}$ & $\begin{array}{l}\text { Meatpacking } \\
(n=896) \\
S M R\end{array}$ & $\begin{array}{l}\text { Grocery stores } \\
(n=3622) \\
S M R\end{array}$ & $\begin{array}{l}\text { Chicken plants } \\
(n=4845) \\
S M R\end{array}$ & $\begin{array}{l}\text { Non-meat (control) } \\
(n=1095) \\
S M R\end{array}$ \\
\hline $\begin{array}{l}\text { All causes (ICD 001-998) } \\
\text { Benign neoplasms } \\
\text { (ICD 210-239) } \\
\text { Allergic, endocrine, metabolic, } \\
\text { nutritional (ICD 240-279) } \\
\text { Diabetes (ICD 250) } \\
\text { All diseases of circulatory system } \\
\text { (ICD 390-458) } \\
\text { Arteriosclerotic heart disease } \\
\text { (ICD 410-413) } \\
\text { All external causes of death } \\
\text { (ICD 800-998) }\end{array}$ & $\begin{array}{l}0.97(1 \cdot 10)^{*} \\
O=535 \\
2 \cdot 17(2 \cdot 42)^{*} \\
O=7 \\
1 \cdot 01(1 \cdot 14) \\
O=16 \\
0 \cdot 94(1 \cdot 06) \\
O=12 \\
0 \cdot 98(1 \cdot 12) \\
O=203 \\
1 \cdot 08(1 \cdot 24)^{*} \\
O=123 \\
0 \cdot 75(0.83) \\
O=38\end{array}$ & $\begin{array}{l}0.83(0.94) \\
O=87 \\
1 \cdot 63(1 \cdot 83) \\
O=1 \\
0 \cdot 66(0 \cdot 74) \\
O=2 \\
0 \cdot 40(0.45) \\
O=1 \\
0 \cdot 97(1.09) \\
O=40 \\
0.86(0.98) \\
O=20 \\
0 \cdot 64(0 \cdot 71) \\
O=5\end{array}$ & $\begin{array}{l}1 \cdot 17(1 \cdot 33) \dagger \\
O=101 \\
\bar{O}=0 \\
1 \cdot 61(1 \cdot 84) \\
O=4 \\
1 \cdot 49(1 \cdot 71) \\
O=3 \\
0 \cdot 99(1 \cdot 16) \\
O=32 \\
1 \cdot 12(1 \cdot 32) \\
O=20 \\
1 \cdot 34(1 \cdot 46) \\
O=10\end{array}$ & $\begin{array}{l}0.91(0.97) \\
O=171 \\
1 \cdot 73(1 \cdot 84) \\
O=2 \\
0 \cdot 57(0 \cdot 60) \\
O=3 \\
0 \cdot 48(0.51) \\
O=2 \\
0.98(1 \cdot 04) \\
O=61 \\
0.98(1.03) \\
O=33 \\
0.53 *(0.56) \\
O=11\end{array}$ & $\begin{array}{l}1 \cdot 18(1 \cdot 26) \\
O=21 \\
\bar{O}=0 \\
\bar{O}=0 \\
\bar{O}=0 \\
1 \cdot 29(1 \cdot 35) \\
O=7 \\
2 \cdot 07(2 \cdot 15) \\
O=6 \\
0 \cdot 39(0 \cdot 43) \\
O=1\end{array}$ & $\begin{array}{l}1.08(1 \cdot 37) \ddagger \\
O=132 \\
6 \cdot 49 \ddagger(8 \cdot 17) \ddagger \\
O=4 \\
1 \cdot 94(2 \cdot 41)^{*} \\
O=7 \\
2 \cdot 00(2 \cdot 47)^{*} \\
O=6 \\
1 \cdot 10(1 \cdot 41)^{*} \\
O=59 \\
1 \cdot 41^{*}(1 \cdot 80) \ddagger \\
O=42 \\
0.91(1 \cdot 14) \\
O=8\end{array}$ \\
\hline
\end{tabular}

$\mathrm{O}=$ Observed number of deaths.

${ }^{*} \mathrm{p}<0.05 ; \uparrow \mathrm{p}<0.01 ; \ddagger \mathrm{p}<0.001$

6923 individuals were divided into their respective job categories and compared separately with the United States white female population through the estimation of cause specific standardised mortality ratios (SMR). A total of 535 deaths occurred among this group.

\section{Results}

Deaths among subjects lost to follow up are suspected to be negligible since an active search found no death certificates for them. Thus two estimates of cause specific SMRs for all the major organs and systems were calculated; one assuming all those lost to follow up were alive at the end of the study and the other, that those lost to follow up were withdrawn at the time of loss. Only SMRs statistically significant by either estimate in any job category are given in the table. The age distributions in the different job categories were virtually identical, hence the SMR for a given cause is directly comparable across job categories.

\section{ALL UNION MEMBERS (white women)}

The all causes SMR was 0.97 (assuming subjects lost to follow up were alive) and $1 \cdot 10, p<0.05$ when subjects lost to follow up were withdrawn at the time of loss. The SMR for benign neoplasms of $2 \cdot 17$ (assuming subjects lost to follow up were alive) was not statistically significant; however, when lost subjects were withdrawn at the time of loss, the SMR was $2.42, \mathrm{p}<0.05$. Similarly, the SMR for arteriosclerotic heart disease of 1.08 was not significant (assuming lost subjects were alive); when those lost were withdrawn at the time of loss, however, the SMR was $1 \cdot 24, p<0.05$. No other cause of death was statistically significant by either estimate.

\section{A B A T TOIR WORKERS}

The all causes SMRs of 0.83 and 0.94 by either estimate did not differ significantly from unity. Similarly, no cause specific SMR was statistically significant by either estimate. No deaths were observed for certain causes of death because of inadequate sample size in this group. Apart from ICD 680-709 (all diseases of skin and cellular tissue), however, a threefold excess risk would have resulted in at least one death observed for each of all the other causes of death.

\section{MEATPACKING PLANT WORKERS}

The all causes SMR for this group was $1 \cdot 17$ (not significant) when subjects lost to follow up were assumed alive at the end of the study. When lost subjects were withdrawn at the time of loss, however, the all causes SMR was $1.33, p<0.01$. No cause specific SMR was statistically significant by either estimate. No deaths were observed for certain causes of death. Apart from ICD 680-709, however, at most a fourfold risk was required to observe one death for any cause of death.

\section{GROCERY STORES/SUPERMARKETS MEAT DEPARTMENT WORKERS}

The SMRs for the all causes mortality by both estimates were 0.91 and 0.97 , none of which was statistically significant. The only statistically significant SMR was that of $0.53, p<0.05$ for all external causes of death (ICD 800-998), assuming lost subjects were alive; the corresponding SMR of 0.56 , with lost subjects withdrawn at the time of loss was not significant. The sample size in this group was adequate, and only for ICD 680-709 was an excess risk required to observe at least one death. 
CHICKEN SLAUGHTERING PLANT WORKERS There were only 21 deaths in this group and the estimates of the all causes SMR of $1 \cdot 18$ and 1.26 were not statistically significant. No cause specific SMR was statistically significant by either estimate. Except for the more common causes of death, however, the number of deaths in this group was inadequate to investigate cause specific mortality.

\section{WORKERS IN NON-MEAT COMPANIES (control group)}

The all causes SMR of 1.08 (assuming lost subjects were alive) was not significant; however, the corresponding SMR of 1.37 (lost subjects withdrawn at time of loss) was statistically significant, $p<0.001$. The SMRs of 6.49 and 8.17 obtained by both estimates respectively for benign neoplasms (ICD 210-239) were highly significant, $p<0.001$. The SMRs for ICD 240-279 (allergic, endocrine, metabolic, nutritional diseases) assuming lost subjects were alive, and with lost subjects withdrawn at the time of loss, were 1.94 and 2.41 respectively, the latter SMR being significant, $\mathrm{p}<0.05$. This excess was exclusively from diabetes (ICD 250); as can be seen, the respective SMRs for diabetes were 2.00 and 2.47 , with the latter SMR again being significant, $\mathrm{p}<0.05$. The SMR for ICD 390-458 (all diseases of circulatory system) was $1 \cdot 10$ (not significant), assuming lost subjects were alive, and $1.41, \mathrm{p}<0.05$, if lost subjects were withdrawn at the time of loss. Similarly, the respective SMRs for ICD 410-413 (arteriosclerotic heart disease and CHD) were $1.41, \mathrm{p}<0.05$, and $1 \cdot 80$, p $<0.001$. Apart from ICD 680-709, the sample size was large enough to observe at least one death if there was a threefold or higher risk of death.

\section{Discussion}

Total mortality among all the white women in this union was not significantly different from that among white women in the United States general population. On examination of the study group by the four main job categories within the meat industry, similar results were observed for all categories except meatpacking plant workers. Although among meatpacking plant workers the all causes SMR of 1.33 was statistically significant, $\mathrm{p}<0.01$ (when subjects lost to follow up were withdrawn at the time of loss), the all causes SMR of 1.37 among the control group of women in the same union who worked in non-meat companies (such as soft drinks manufacturing or oyster shucking) was also statistically significant, $p<0.001$ (when subjects lost to follow up were withdrawn at the time of loss). If subjects who were lost to follow up were assumed to be alive at the end of the study, however, all causes SMRs of 1.17 and 1.08 which were not significant were obtained for these two categories of workers. These results suggest that even if this excess. mortality among meatpacking plant workers is reat. the high background mortality may be contributor also. It is well known that mortality in the gener䊁 population of Baltimore city from which over $60 \%$ of the study group was derived was much higher than that in the United States general population, SMR 든 1.26 (A Gittelsohn, report to National Center fof Health Statistics, 1981). It is to be noted that the onl$\vec{\Phi}$ cause of death likely to be responsible for this appar ent excess mortality among meatpacking workers would be mortality from cancers, as this was the onl\$ cause of death significantly raised in this group but not in the control group. We have previously reported in detail our findings on cancer mortality in this study group. ${ }^{12}$

No non-malignant cause of death was significantl raised in any of the job categories within the meat industry. This suggests that except for cancers the meat industry is not otherwise associated wit unusual mortality among female workers. Thes results are not surprising. A comparatively clea working environment, engagement in less hazardous activities, stricter health requirements for employe ment, and good medical surveillance and care (factors that are known to prevail within the meat industry would possibly explain these results for women.

The excess risk of death from benign neoplasm among the entire study group seemed to have orig nated exclusively from among the control group? SMR 6.49 or 8.17 ( $p<0.001)$. A similar pattern wa $\overrightarrow{\bar{s}}$ observed for arteriosclerotic heart disease. Thus it reasonable to conclude that these diseases are nof associated with the meat industry and that their. excess among the control group probably reflects the background mortality. It is interesting that we ha@ observed a similar risk for benign neoplasms among similar control group of male workers in the same. union. ${ }^{13}$ We do not have any explanation for the excess of diabetes in the control group except that may be due to chance or reflect background rates. $\mathrm{AQ}$ already mentioned, this group of women comprised a heterogenous group from several occupation groups outside the meat industry. The interpretatio of our finding of an absence of excess risk from non malignant causes of death among women in the meant industry should be tempered with caution, howevef్రు particularly with respect to workers in chicke日 slaughtering plants since the number of deaths in this group was too few to assess adequately cause specific risk.

This study was supported by Grant CA 30410-3 fror the National Cancer Institute. 


\section{References}

I Vandervort R, Brooks SM. Polyvinyl chloride film thermal decomposition products as an occupational illness. $J$ Occup Med 1977;19:188-91.

2 Burmester BR, Purchase HG. Occurrence, transmission and oncogenic spectrum of the avian leukosis viruses. Bibl Haematologica 1970;36:83-95.

3 United States Department of Agriculture. Meat and poultry inspection program. Food safety and quality service. Statistical summary-federal meat and poultry inspection for calendar year 1978. Boston: United States Department of Agriculture, 1979.

4 Nazerian K. Marek's disease lymphoma of chicken and its causative herpesvirus. Biochim Biophys Acta 1979;560:375-95.

5 Olson C. Bovine lymphosarcoma (leukaemia)-a synopsis. J Am Vet Med Assoc 1974;65:630-2.

6 Copplestone JF, Kaplan J. Encyclopedia of occupational health and safety. Geneva: International Labour Office, 1972:2-228.

7 Ito N, Hirose M, Kurata Y, Ikawa E, Mera Y, Fukushima S. Induction of forestomach hyperplasia by crude butylated hydroxyanisole, a mixture of 3-tert and 2-tert isomers, in Syrian golden hamsters is due to 3-tert-butylated hydroxy- anisole. Gann 1984;5:471-4.

8 Sen NP, Donaldson B, Charbonneau C, Miles WF. Effect of additives on the formation of nitrosamines in meat curing mixtures containing spices and nitrite. J Agric Food Chem 1974;22:1125-30

9 Tsuda H, Fukushima S, Imaida K, Sakata T, Ito N. Modification of carcinogenesis by antioxidants and other compounds. Modifiers of carcinogenesis: proceedings from the symposium in Copenhagen, 22-23 September, 1983. Acta Pharm et Toxicol 1984;55:suppl 1.

10 International Agency for Research on Cancer. Monographs on the evaluation of the carcinogenic risk of chemicals to humans. Vol 17. Some N-nitroso compounds. Lyon: IARC, 1978:51-75, 83-125, 287-335.

11 Wegman DH. Study of respiratory effects in the retail food industry. (Draft of the final report to the SPI-PVC meat wrap committee/joint labour management committee. Occupational health program.) Harvard School of Public Health, 1983.

12 Johnson ES, Fischman HR, Matanoski GM, Diamond E. Cancer occurrence in women in the meat industry. $\mathrm{Br} J$ Ind Med 1986;43:597-604.

13 Johnson ES. Non-cancer mortality in the meat industry-white males. J Occup Med (in press). 